\title{
Suppression of Dominant Topographic Overprints in Gravity Data by Adaptive Filtering: Southern Wyoming Province
}

\author{
ROSS A. BLACK
}

Department of Geology, University of Kansas, Lawrence

\begin{abstract}
In areas of the world with a protracted tectonic history, the gravity field may be dominated by anomalies due to individual structural features developed during the latest tectonic event. These individual tectonic features often have a topographic expression. Adaptive filtering techniques can be used to suppress the gravity effects of such features. Iterative space domain techniques are particularly well suited to these types of problems. One such technique, the stochastic gradient algorithm, allows easy updating of filter coefficients at each spatial step through the data. This approach eliminates windowing and spectral estimation problems associated with cross-spectral admittance schemes. In this study, adaptive filtering of Bouguer gravity and topography in the southern Wyoming Province was successful in suppressing gravity signatures of Laramide structural features. The regional gravity trends due to isostatic effects were significantly absent from the residual anomaly map. A large, continuous, positive gravity anomaly stretching from the southern Wind River Range to the northern end of the Laramie Range was another outstanding feature observed in the residual anomaly. This positive anomaly is about the same magnitude, size and shape as anomalies due to greenstone belis observed in other Archean cratonal areas. Scattered occurrences of greenstone lithologies are known throughout the area of the anomaly, but a continuous feature is absent in outcrop. Due to the unusual structural history of the area, it is possible that such a continuous belt does exist, but was buried at shallow crustal levels by Laramide thrusting, or later collapse of a Laramide uplift due to a change in the regional stress field.
\end{abstract}

\section{INTRODUCTION}

In areas of the world with a protracted tectonic history, the gravity field may be dominated by anomalies due to individual structural features developed during the latest tectonic event. These individual tectonic features often have a topographic expression. Although gravity data are typically processed through a suite of standard reductions, the topographic effects can dominate even after standard gravity reduction procedures have been utilized.

In this study a two-dimensional space domain technique is developed capable of separating the gravity field into those components associated with the latest deformational topographic overprint and those features associated with the predeformational geology of the area. To demonstrate its utility, the technique is applied to a data set within the area of the North American Cordilleran affected by the Cenozoic Laramide orogeny. The development of the technique is completely general, however, and can be applied in any tectonic area where topographic effects may mask gravity anomalies of interest.

The Wyoming Province, an Archean cratonal block, has been subjected to multiple deformational events from the Proterozoic through the Cenozoic. The most recent major orogenic event affecting the eastern potion of the Province is the Cenozoic Laramide Orogeny. This event produced many distinctive uplifts and foreland basins, which dominate the topography observed in much of the eastern Cordilleran today. The topography due to the Laramide deformation has an enormous influence on the gravity field

\section{Copyright 1992 by the American Geophysical Union.}

Paper number 92JB01200.

0148-0227/92/92JB-01 200\$05.00 within the area. This large Laramide effect masks gravity anomalies due to older features of interest.

Theoretical isostatic/flexural models predict that Bouguer anomalies will be be correlated with topography, assuming a lithosphere of finite flexural rigidity [Forsyth, 1985; McNutt, 1990]. While these models may be fairly accurate for simple, young lithosphere, the assumptions used in these models are rarely met in geologically complex areas, and residual isostatic anomalies, uncorrelated with topography, are indeed observed [Forsyth, 1985]. Regional [Simpson et al., 1986] and detailed [Hall and Chase, 1989] studies of the gravity field in Wyoming Province have indicated that simple isostatic/flexural models are difficult to apply in this area. Individual mountain ranges are not properly compensated and portions of the Province may have undergone complex, timedependent changes in rheology. In addition, horizontal buckling and collapse due to stress relaxation were probably dominant mechanisms during the later Cenozoic history of the area [Hall and Chase, 1989]. The geologically complex southern Wyoming Province is thus an area where the Bouguer gravity field may include a relatively significant component uncorrelated with Laramide age structural/topographic features.

In this study, the gravity field associated with the southern Wyoming Province is decomposed into Laramide and pre-Laramide elements. The method utilized to perform the decomposition is the signal processing technique known as joint process adaptive filtering. This filtering process allows the decomposition of a data vector into components correlated and uncorrelated with a separate noise vector [Honig and Messerschmitt, 1984]. Since the Laramide tectonic features are highly correlated with the topography within the Cordillera, topographic data were used as the noise reference. One of the great advantages of 
the adaptive filtering technique is that no particular lithospheric model needs to be assumed in filtering applications.

\section{PREVIOUS STUDIES}

Before beginning the theoretical development of the adaptive filtering algorithm used in this study, it should be pointed out that decomposition of the gravity field on the basis of topographic correlation is not a new idea. Dorman and Lewis [1970] utilized cross-spectral techniques to study isostatic gravity anomalies and crustal compensation within the continental United States. The study of lithospheric properties is still the major area in which such techniques are applied [Banks et al., 1977; McNutt and Parker, 1978; McNutt, 1978, 1979,1983; and Londe, 1986].

The basic assumption underlying the technique is that a linear relationship exists between the topography and the gravity field of its isostatic mass compensation. In this study this assumption is extended. Here the assumption is that a linear relationship exists between the combination of all perturbations of the gravity field due to topography and the topography itself. This allows the spatial gravity field to be written as a convolution of the topography with a transfer function which represents the gravity field of a topographic point load [Dorman and Lewis, 1970].

In all previous studies, this transfer function was investigated in the spatial frequency domain. The frequency domain transfer function (admittance function) can be inverted using simple analytical compensation models to determine lithospheric flexual rigidity and depth of compensation [Banks et al., 1977]. The admittance function is the main feature of interest in this type of approach. The objective of these studies is to find the large-scale relationship between the gravity field and the topography. The residual field uncorrelated with topography is considered noise of little interest. In this study the opposite is true. This noise is really the residual gravity field of interest. It is the component uncorrelated with the Laramide structures.

At least one author has looked at the residual from a frequency domain potential field/topographic decomposition. Clarke [1971] utilized the Dorman and
Lewis [1970] approach in a three-dimensional model study of magnetic data, where the residual was considered important for exploration purposes. The technique was never applied to a real data set, however.

One of the problems with the admittance function approach is that boundaries between major tectonic provinces and even subprovinces can cause inaccurate spectral estimates [Londe, 1986; C. Angevine, personal communication, 1988]. Such effects can be minimized by judicious choices of Fourier transform window size, overlap, and weighting, but these complications make interpretation of the residual field difficult [Londe, 1986]. In the adaptive filtering approach the filter (the transfer function) is calculated in the space domain and allowed to continuously adapt to the data at each spatial step. This approach allows the filter characteristics to smoothly adapt to changes in the relationship between gravity and topography across an area of study.

\section{ADAPTIVE FILTERING}

The joint process adaptive filter can be viewed as a black box which has two sets of input data and one output data stream (Figure 1). The primary input consists of desired signal plus noise, while the secondary or reference input consists of noise only. The noise at the reference input is assumed to be correlated with, but not necessarily the same as, the noise corrupting the signal at the primary input. It is the job of the adaptive filter to continuously estimate the transfer function between the reference noise and the primary input. This transfer function is then applied to the reference noise, yielding an estimate of the true noise. The resulting noise estimate can be subtracted from the primary input to yield an estimate of the signal only. The notation used in the following development will strongly reflect the application of the algorithm to the Laramide/pre-Laramide problem discussed later at length. In the current application, the primary input $\mathrm{g}_{\mathrm{obs}}(\mathrm{x})$ (the observed gravity data) is defined as:

$$
\mathrm{gobs}_{\mathrm{o}}(\mathrm{x})=\mathrm{g}_{\mathrm{pL}}(\mathrm{x})+\mathrm{gL}_{\mathrm{L}}(\mathrm{x})
$$

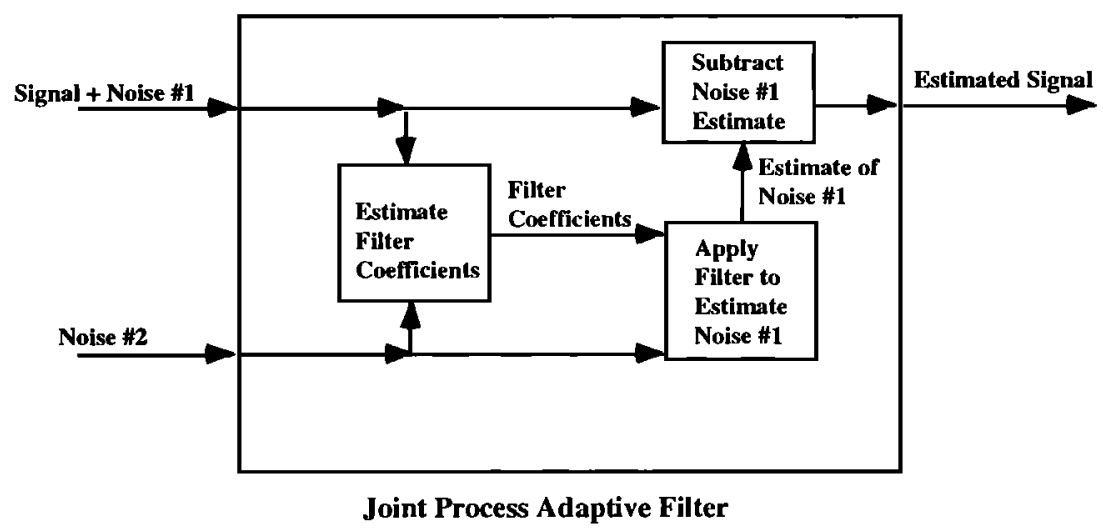

Fig 1. Schematic diagram of a joint process adaptive filter. There are two data streams being input and one data stream being output from the filter. The primary input consists of the desired signal corrupted by noise. The secondary input consists of noise only. The statistical assumptions are that the signal is uncorrelated with both noise streams, and that the primary noise is correlated with (but not necessarily the same as) the secondary noise. The output is an optimum estimate of the original signal. 
The gravity data consist of $\mathrm{g}_{\mathrm{L}}(\mathrm{x})$, the gravitational effect due to Laramide structures and $\mathrm{g}_{\mathrm{pL}}(\mathrm{x})$, the gravitational effect due to pre-Laramide lithologic variations. A basic assumption made is that $\mathrm{gL}_{\mathrm{L}}(\mathrm{x})$ and $\mathrm{g}_{\mathrm{pL}}(\mathrm{x})$ are uncorrelated. The $g_{L}(x)$ term is assumed here to include two effects, the direct gravity effect of the structure and the isostatic/flexural effect. These effects should be correlated with the presentday topography $t(x)$ within the study area. The transfer function between $g_{L}(x)$ and topography is a filter of unknown character. The problem, then, is to calculate the coefficients of this filter somehow from the data. If an estimate can be made of these filter coefficients, then they can be convolved with the topographic data to yield an estimate $\mathrm{gestL}_{\mathrm{L}}(\mathrm{x})$ of $\mathrm{g}_{\mathrm{L}}(\mathrm{x})$. This can be written as:

$$
\operatorname{gestL}(x)=c(x) * t(x)
$$

Where $t(x)$ is topography and $g_{\text {estL }}(x)$ is the estimate of $g_{L}(x)$ output by the filter. Subtracting this estimate from the observed data yields an estimate of the pre-Laramide gravity effects.

$$
\operatorname{gestpL}(x)=g_{o b s}(x)-g_{e s t L}(x)
$$

which, again, is our desired result. This result arises from the fact that $g_{\operatorname{estpL}}(x)$ is an estimate of the only part of gobs $(x)$ not correlated with $t(x)$. It is the "error" term in the signal processing sense. This error will only go to zero in degenerative cases [Honig and Messerschmitt,1984]. The optimum estimate will thus minimize some error measure such as le(x)l or $\mathrm{e}^{2}(\mathrm{x})$ over all $\mathrm{x}$. To find this (L2 norm) minimum, the expectation of $\mathrm{e}^{2}(\mathrm{x})$ is taken. Since:

$$
e(x)=g_{e s t p L}(x)
$$

substituting the results of equations (1) and (3) into equation (4), squaring and taking the expectation gives:

$$
E\left[e^{2}(x)\right]=E\left[g^{2} p(x)\right]+E\left[\left(g_{L}(x)-g_{e s t L}(x)\right)^{2}\right]
$$

$\mathrm{E}\left[\mathrm{g}^{2} \mathrm{pL}(\mathrm{x})\right]$ is a constant, so the only way to vary the value of the left-hand side of equation (5) is to vary the difference betweenb $g_{L}(x)$ and $g_{e s t L}(x)$ on the right-hand side. This implies that the best estimate will occur when the mean-square error is minimized, as stated above. The estimate $\mathrm{gestL}_{\mathrm{L}}(\mathrm{x})$ can be written as:

$$
\begin{gathered}
g_{e s t L}(x)=C^{\prime} T(x) \\
C^{\prime}=\left[\begin{array}{llll}
c_{1} & c_{2} & \ldots . & c_{n}
\end{array}\right] \\
T^{\prime}(x)=\left[\begin{array}{llll}
t(x+n / 2) \ldots . t(x) \ldots . t(x-n / 2)
\end{array}\right]
\end{gathered}
$$

where $C$ is a vector of $\mathbf{n}$ filter coefficients which represent the transfer function between $t(x)$ and $g_{\text {estL }}(x)$. In practice, $C$ can also be a function of $x$. $T(x)$ is a vector of the $n$ samples of the reference noise $t(x)$ symmetric about the current point $x$. The prime denotes the vector transpose. Now substituting equation (6) into equation (3), the output error can be written as:

$$
\text { gestpL }(x)=g_{o b s}(x)-C^{\prime} T(x)
$$

Equation (9) and equation (3) are equivalent. The unknown on the right side of equation (9) is the filter coefficient vector. The coefficients can be solved for simply by standard least squares matrix techniques [Dorman and Lewis, 1970], if the data are stationary or if windowing the data presents no problems. An iterative gradient technique, the stochastic gradient algorithm (SGA), can be used alternatively to solve for the coefficients at each point. This approach avoids the stationarity and windowing problems [Honig and Messerschmitt, 1984].

In the SGA a simple iterative update procedure is used to recalculate the filter coefficients at each point without having to explicitly solve a system of equations. The basis for the algorithm is the recognition of the fact that the squared error is also minimized when the gradient (in terms of the filter coefficients) is zero:

$$
\nabla_{c}\left\{E\left[e^{2}(x)\right]\right\}=\nabla_{c}\left\{E\left[g^{2} \text { estL }(x)\right]\right\}=0
$$

or, differentiating:

$$
-2 E[\operatorname{gestL}(x) T(x)]=0
$$

Now, in practice the ensemble statistics are never known, and thus the expectation cannot truly be calculated. If we simply drop the expectation operator, we are left with a "noisy" or stochastic gradient which is an unbiased estimate of the true gradient [Honig and Messerschmitt, 1984]:

$$
-2 \operatorname{gestL}(x) T(x)=0
$$

A solution for the coefficient vector at the new time or spatial step, $C(x+1)$, is simply the solution at the last step plus or minus a value representing a step in the direction of the maximum gradient. Here:

$$
C(x+1)=C(x)-(\beta / 2) \nabla_{c}\left\{E\left[e^{2}(x)\right]\right\}
$$

where $\beta / 2$ is the size of the step in the direction of the gradient. Dropping the expectation operators and substituting equation (12) into equation (13) yields:

$$
C(x+1)=C(x)+\beta g_{e s t L}(x) T(x)
$$

which is the equation for updating the filter coefficients used in the SGA. The value of $\beta$ is usually a few percent of the value of the data variance. The coefficients found using equation (14) are then applied to the data using equation (9) to yield the output $\mathrm{gestpL}_{\mathrm{e}}(\mathrm{x})$ at each spatial step.

To implement the filter in a two-dimensional form, the functions of $x$ are simply rewritten as functions of both $x$ and $y$. Also, the sliding windows of equation (8) and the filter vector $C$ must be defined to be composed of elements from a two-dimensional window surrounding the current $x, y$ point. All other steps remain the same, but the data are stepped through in two dimensions.

\section{WYOMING PROVINCE DATA}

In order to test the method proposed, gravity and topography data from an area within the Cordillera which exhibits a strong Laramide topographic overprint normal to 
the strike of the major Precambrian tectonic features were chosen. This area encompasses a portion of an Archean cratonal area known as the southern Wyoming Province.

The data used in this study consisted of elevation and gravity anomaly information taken from standard topography and gravity tapes available from the National Geophysical Data Center. The raw topographic data were in $\mathbf{3 0}$ second grid format, while the gravity information was in an ungridded latitude, longitude, and anomaly value format on the tapes. Although three separate gravity values, observed, free air, and simple Bouguer, were available on the tapes, only the Bouguer values were used in this study.

For the analysis of the southern Wyoming Province, all of the data between $41^{\circ}$ and $45^{\circ} \mathrm{N}$ latitude and between $104^{\circ}$ and $111^{\circ} \mathrm{W}$ longitude (essentially the area within the state of Wyoming) were gridded at $3 \mathbf{~ k m}$ intervals on a Universal Transverse Mercator projection utilizing a standard U.S. Geological Survey minimum-curvature gridding routine. This procedure yielded two identically dimensioned gridded data sets of 199 points in the east-west direction and 155 points north to south. Contour maps of the gridded data sets (Figures 2 and 3) were constructed with contour intervals of $600 \mathrm{~m}$ for the topography and 40 $\mathrm{mGal}$ for the Bouguer gravity values.

Before adaptive filtering both the topography and the Bouguer gravity data were normalized to a range of plus or minus 1 to insure numerical stability. The adaptive filter

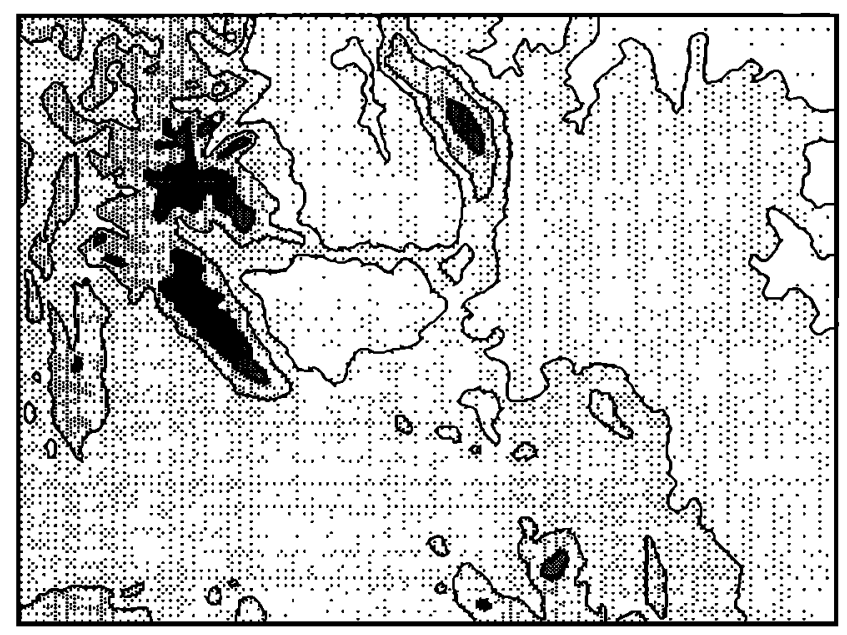

Explanation

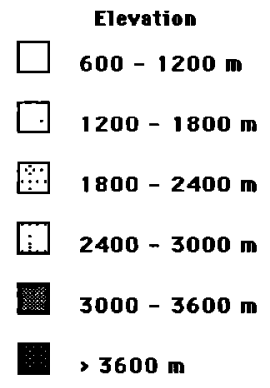

Fig 2. Generalized topographic map of the region between $104^{\circ}$ and $111^{\circ} \mathrm{W}$ longitude and $41^{\circ}$ and $45^{\circ} \mathrm{N}$ latitude (approximately the area of the state of Wyoming). The original data were regridded at $3 \mathrm{~km}$ intervals on a UTM projection. Contour interval is $600 \mathrm{~m}$. was then applied to the data sets. The resulting residual values were smoothed with a nine point space domain, moving-average operator, rescaled and contoured at $20 \mathrm{mgal}$ intervals. The major feature of the residual field (Figure 4) is the lack of any broad regional slope in the field from west to east due to isostatic effects. The technique applied here seems to have performed a rather effective isostatic correction, similar to that of Simpson et al. [1986], without having to have assumed any particular compensation model. In their work with the isostatic residual anomaly values in this area those investigators found that there was an isostatic residual high associated with each of the Laramide uplifts. Obviously, this is not the case with the output from the adaptive filter (Figure 4). While the adaptive filter did apparently remove the longwavelength isostatic effects, it also strongly attenuated the short-wavelength anomalies due to several of the major uplifts. The one notable exception is the anomaly associated with the Sweetwater Uplift which trends from west to east from the southern end of the Wind River Range to the northern portion of the Laramie Range. Today this uplift is represented mainly by the presence of two small ranges, the Granite and Seminoe mountains (Figure 5). These ranges represent only small remnants of what was once a much larger uplifted feature. The Sweetwater Uplift and the southern Wind River Range were topographically much higher areas during the Laramide orogeny, shedding sediments off of their flanks into the

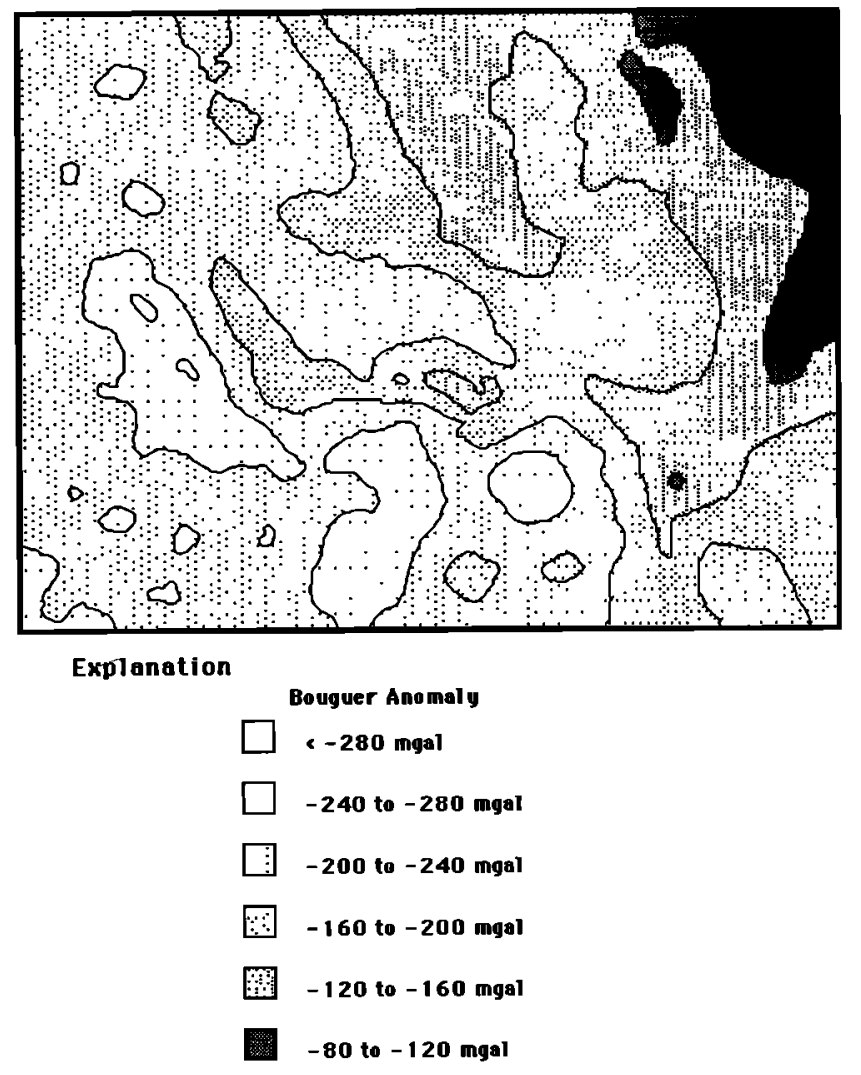

Fig 3. Generalized Bouguer gravity anomaly map of the region between $104^{\circ}$ and $111^{\circ} \mathrm{W}$ longitude and $41^{\circ}$ and $45^{\circ} \mathrm{N}$ latitude (approximately the area of the state of Wyoming). The data were gridded from raw data at $3 \mathrm{~km}$ intervals on a UTM projection. Contour interval is $40 \mathrm{mGal}$. 


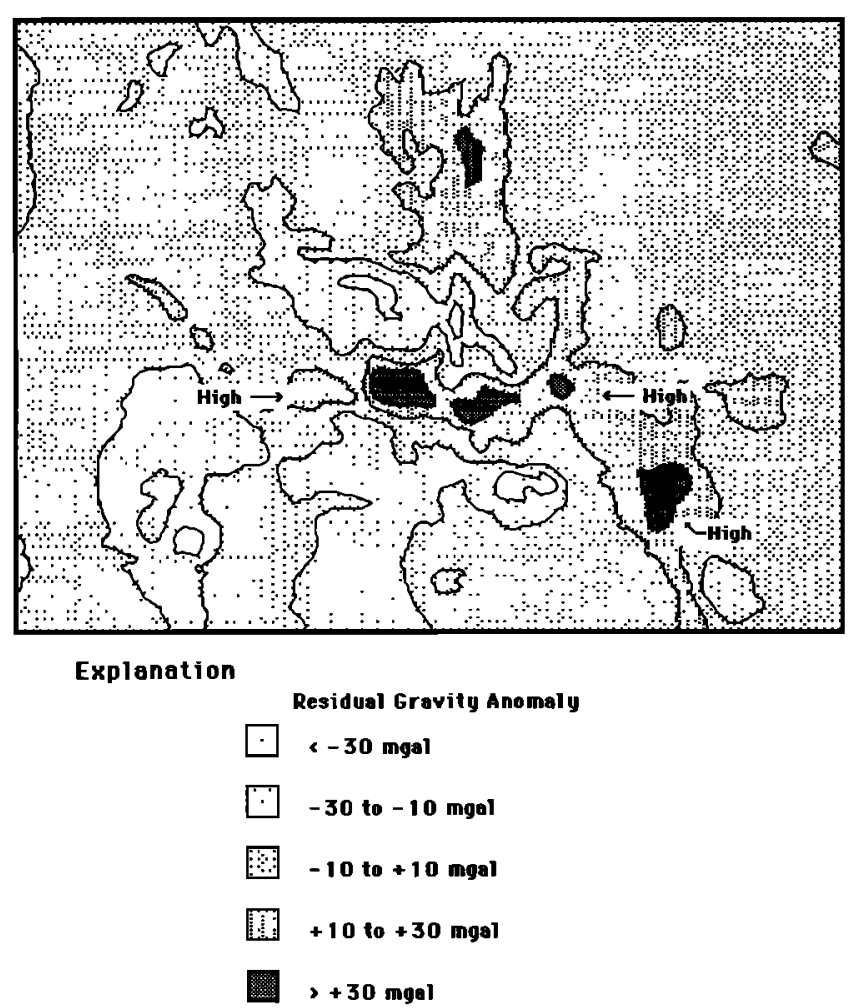

Fig 4. Estimated gravity "signal" of pre-Laramide effects found by adaptive filtering of the data from Figures 2 and 3 . Note strong, continuous gravity high running west to east across the center of the state. This anomaly may be due to a previously unrecognized greenstone belt buried at depth. surrounding basins, much like the other major uplifts [Love, 1970; Steidtmann et al., 1983, 1986, 1989]. Unlike the other major uplifts, however, this feature subsided sometime during the Cenozoic due to flexural considerations in response to a changing regional stress field [Hall and Chase, 1989]. Today, although there is a small topographic expression (Figure 2), the old uplift is mostly buried by later Cenozoic deposits.

The lithology dominating the central portion of the Granite and Seminoe mountains is Archean intrusive granite (Figure 5). However, Archean metasedimentary and metavolcanic sequences are observed around the periphery of the ranges in some volume. Love [1970] noted metasediments including a sequence of black and green schists, slate, phyllite and quartzite with associated diorites in the Granite mountains. These units resemble and are on general trend with the Archean greenstones investigated by Bayley et al., [1973] in the South Pass area of the Wind River Range. Other possible greenstone successions have been noted by Klein [1980] in the Seminoe Range. In addition, the Elmer's Rock greenstone occurs in the central portion of the Laramie Range (Figure 5) and other metasedimentary and metavolcanic successions exist in the northern Laramie Range. Historically, these greenstone assemblages have not been generally regarded as defining a coherent greenstone belt because of their scattered occurrence and the fact that the very limited, unpublished radiometric dating information available indicates that there may be two separate greenstone successions with ages of 2.7 Ga and 3.0 Ga within the area [R.Houston, personal communication, 1988].

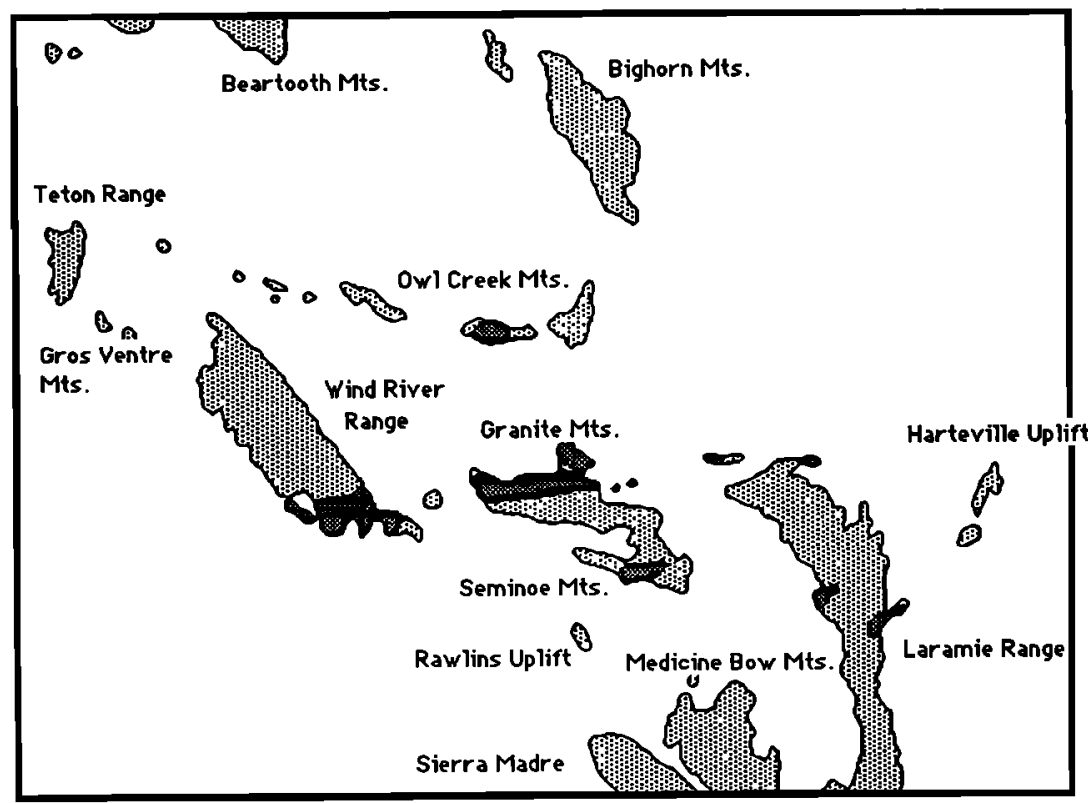

Explanation

Exposed Precambrian

Precambrian - no Archean greenstones

Archean metasedimentary and metavolcanic rocks with greenstone affinities

Fig 5. Location of exposed Precambrian rocks in Wyoming. Darker stipple indicates locations of rocks with greenstone affinities (modified from Karlstrom et al., [1981]). Note that these outcrops occur around the periphery of the positive gravity residual interpreted to be due to a buried greenstone belt. 
In general, however, there seems to be a trend in the area of the strong east-west residual gravity high (Figure 4), of relatively small, but significant occurrences of possible greenstone lithologies. In an area in which rock sample densities have been studied, Hurich and Smithson [1982] modeled the greenstones observed in the South Pass area as causing a significant portion of the positive gravity anomaly in the area. The possibility of there being a subsurface extension of the South Pass greenstones to the east was first proposed by Black et al., [1987] on the basis of gravity data. Forward modeling studies by Hall and Chase [1989] in the western portion of the area indicate that an unusually dense body must exist at depth below the Granite mountains. From their calculations, they concluded that the unusually high positive gravity anomalies and sharp gravity gradients in the area were probably due to the existence of greenstones at depth. The alternative interpretation is that unrealistically rapid crustal thinning occurs immediately below the range. Since the Laramide ranges are undercompensated under normal crustal thickness conditions [Simpson et al., 1986] and since there is no seismic evidence for local crustal thinning, this alternative is probably not a viable one.

The above studies seem to strongly suggest that the continuous positive gravity high extending from the southern Wind River Range in the west to the northern Laramie Range in the east is caused by a fairly continuous greenstone belt at depth, a conclusion supported by the scattered occurrences of greenstone lithologies in surface outcrop throughout the area. The residual anomaly is of the same magnitude, shape and size as anomalies associated with greenstone belts in other Archean cratonal areas. The continuity of this anomaly is the first geophysical evidence for the continuity of the belt. The continuity of the anomaly is also evidence that if there are two ages of greenstone successions in the area, one is probably dominant. Further work remains to determine whether it is the $2.7 \mathrm{Ga}$ or $3.0 \mathrm{Ga}$ aged unit that forms the belt in the subsurface.

\section{CONCLUSIONS}

The joint process adaptive filtering scheme has been presented and shown to be useful in decomposing a gravity data set into components correlated and uncorrelated with topography. The technique thus works well in suppressing topographic overprints in the gravity field. Although other approaches to the problem have been developed, by utilizing the stochastic gradient algorithm most of the problems associated with calculating residuals within the spatial frequency domain are avoided. The filtering process developed here is completely general and applicable to any area where strong topographically correlated overprints occur within the gravity field and mask anomalies of interest. It is also applicable to other potential field data sets which may exhibit similar problems.

The adaptive filter allowed enhancement of a general eastwest trending gravity high across central Wyoming. This high is probably caused by a fairly continuous greenstome belt occurring mainly in the subsurface within the collapsed central portion of the Laramide Sweetwater Uplift. A continuous geophysical signature indicating that the greenstone belt is probably a single coherent feature had not previously been recognized.
Acknowledgments: The author is grateful to S. B. Smithson, C. Angevine, D. Fountain, R. Hawman, and S. Key for their valuable insight. The author also thanks $R$. L. Kirlin for introducing the author to the adaptive approach, and M. McNutt for a critical review of this paper.

\section{REFERENCES}

Banks, R. J., R. L. Parker, and S. P. Huestis, Isostatic compensation on a continental scale: local versus regional mechanisms, Geophys. J.R. astron. Soc., 51, 431-452, 1977.

Bayley, R. W., P. D. Proctor, and K. C. Condie, Geology of the South Pass Area, Fremont County Wyoming, U. S. Geol. Surv. Prof. Pap. 793, 39 pp., 1973.

Black, R. A., S. B. Smithson, and R. L. Kirlin, Adaptive filtering of gravity and topography data, western U.S. (abstract), Eos Trans./ AGU, 68, 280, 1987.

Clarke, G. K. C., Linear filters to suppress terrain effects on geophysical maps, Geophysics, 36, 963-966, 1971.

Dorman, L. M. and B. T. R. Lewis, Experimental isostasy, 1, Theory of the determination of the Earth's isostatic response to a concentrated load, J. Geophys. Res., 75, 3357-3366, 1970.

Forsyth, D. W., Subsurface loading and estimates of the flexural rigidity of continental lithosphere, $J$. Geophys. Res., 90, 12623-12632, 1985.

Hall, M. K., and C. G. Chase, Uplift, unbuckling, and collapse: Flexural history and isostasy of the Wind River Range and Granite mountains, Wyoming, J. Geophys. Res., 94, $17,581-17,594,1989$.

Honig, M. L., and D. G. Messerschmitt, Adaptive Filters, Structures, Algorithms and Applications, 337 pp., Kluwer Academic, Boston, Mass., 1984.

Hurich, C. A., and S. B. Smithson, Gravity interpretation of the southern Wind River mountains, Wyoming, Geophysics, 47, 1550-1561, 1982.

Karlstrom, K. E., R. S. Houston, A. J. Flurkey, C. M. Coolidge, A. L. Cratochvil, and C. K. Sever, A summary of the geology and uranium potential of Precambrian conglomerates in SE Wyoming: rep. DJBX-139-81, 551 pp., Bendix Field Engineering Corp., 1981.

Klein, T. L., The geology and geochemistry of the sulphide deposits of the Seminoe District, Carbon Co. Wyoming, Ph.D. dissertation, Colo. Sch. of Mines, Golden, 1980.

Londe, M. D., The Colorado Plateau - Basin and Range Transistion Zone in Central Utah: Termomechanical modeling and spectral analysis of topographic and gravity data, Ph.D. dissertation, 157 pp., Univ. of Wyo., Laramie, 1986.

Love, J. D., Cenozoic Geology of the Granite Mountains Area, Central Wyoming, U. S. Geol. Surv. Prof. Pap. 495-C, 154 pp., 1970.

McNutt, M. K., Continental and Oceanic Isostasy, Ph.D. dissertation, 192 pp., Univ. of Calif., San Diego, La Jolla 1978.

McNutt, M. K., Compensation of oceanic topography: an application of the response function technique to the Surveyor area, J. Geophys. Res., 84, 7589-7598, 1979.

McNutt, M. K., Influence of plate subduction on isostatic compensation in northern California, Tectonics, 2, 399 $415,1983$.

McNutt, M. K., Flexure reveals great depth, Nature, 343, 596598, 1990.

McNutt, M. K., and R. L. Parker, Isostasy in Australia and the evolution of the compensation mechanism, Science, 199 , 773-775, 1978 
Simpson, R. W., R. C. Jacbens, R. J. Blakely, and R. W. Saltus, A new isostatic residual gravity map of the coterminous United States with a discussion of the significance of isostatic residual anomalies, J.Geophys. Res., 91, 3360-3386, 1986.

Steidtmann, J. R., L. C. McGee, and L. T. Middleton, Laramide sedimentation, folding and faulting in the southern Wind River Range, Wyoming, in Rocky Mountain Foreland Basins and Uplifts, Guidebook, edited by J. D. Lowell, pp. 161-168, Rocky Mountain Association of Geologists, Denver, Colo., 1983.

Steidtmann, J. R., L. T. Middleton, R. J.Bottjer, K. E. Jackson, L. C. McGee, E. H. Southwell, and S. Lieblang, Geometry, distribution, and provenance of tectogenic conglomerates along the southern margin of the Wind River Range, Wyoming, Paleotectonics and Sedimentation in the Rocky Mountain Region, U.S., Mem. Am. Assoc. Pet. Geol., 41, 321-332, 1986.

Steidtmann, J. R., L. T. Middleton, and M. W. Shuster, Post Laramide (Oligocene) uplift in the Wind River Range, Wyoming, Geology, 17, 38-41, 1989.

R. A. Black, University of Kansas, Department of Geology, 120 Lindley Hall, Lawrence, KS, 66045.

(Received July 18, 1990;

Revised May 20, 1992;

Accepted May 27, 1992) 